Original Research Article

\title{
Prescription audit to evaluate the pattern and errors in a tertiary care hospital
}

\author{
Poonam Patel, Murtuza Bhora*, Akash Vishwe, P. Nyati, S. Tripathi, Kamayani Gupta
}

Department of Pharmacology, Index Medical College, Indore, Madhya Pradesh, India

Received: 17 September 2019 Accepted: 17 October 2019

\section{*Correspondence to:}

Dr. Murtuza Bhora,

Email: murtz_bohra@ yahoo.co.in

Copyright: (C) the author(s), publisher and licensee Medip Academy. This is an openaccess article distributed under the terms of the Creative Commons Attribution NonCommercial License, which permits unrestricted noncommercial use, distribution, and reproduction in any medium, provided the original work is properly cited

\begin{abstract}
Background: Medication errors are widespread public health issue. Prescription errors commonly results in medication error. Prescription error can be largely avoidable this study was performed with aim to point out the common mistake in the prescription which may endanger patients.

Methods: Our study was cross-sectional and observational, performed in Index Medical College. 320 prescriptions were reviewed. Analysis was done for presence or absence of essential components of prescription like prescriber information's, patients information's, details of drug like its dosage form, strength, frequency, total duration of treatment, warnings or instruction for use. The observed data was expressed in number and percentage.

Results: Patient information was complete 315 (98.44\%) in prescriptions. Prescriber's information were present in 284 (88.75\%). Legibility was seen in $240(75 \%)$. Use of generic drug, capital letters for drug name, warning are seen in $9(2.81 \%), 39(12.19 \%), 3(0.94 \%)$ respectively. Completeness in terms of the name of drug, dose, strength, route, frequency, duration and dosage forms of prescribed drugs was seen in $252(78.75 \%)$ prescriptions.

Conclusions: Properly framed and written prescription can largely prevent medication error. Regular prescription audit must be carried out so that common mistake can be identified and corrective measure with the help of training session, workshop can be taken.
\end{abstract}

Keywords: Prescription audit, Prescription error, Medication error

\section{INTRODUCTION}

Prescription is a written document to take the health care of the patient by the doctor with the involvement of pharmacist or nurse as a chief executive body in pharmacotherapy. If this document is misinterpreted at any level, it can lead to unsafe treatment, exacerbation of the disease, health hazards, and economic burden on the patients and wastage of resources. Medication error includes prescription faults and Prescription errors. Prescription errors account for $70 \%$ of medication errors that could potentially result in adverse effects or the inefficacy of pharmacotherapy. A mean value of prescribing errors with the potential for adverse effects in patients of about 4 in 1000 prescriptions was recorded in a teaching hospital. ${ }^{1-3}$ Recent meta-analysis showed that the range of errors attributable to junior doctors, who are responsible for most prescriptions in hospitals, can vary from 2 to 514 per 1000 prescriptions and from $4.2-82 \%$ of patients. ${ }^{4}$ Prescription errors encompass those related to the act of writing a prescription, whereas prescribing faults encompass irrational prescribing, inappropriate prescribing, under prescribing, overprescribing, and ineffective prescribing, arising from erroneous medical judgement or decisions concerning treatment or treatment monitoring. 1,5 Errors of omission and errors of commission are two main types of described prescription errors. Errors of omission are where a prescription is incomplete in some way, whereas errors of commission contain incorrect information. ${ }^{6,7}$

Beside rational drug prescription, correct format of the prescription also play important role. The World Health Organization (WHO) suggests the minimum set of information's as core elements to be mentioned on a prescription order to ensure good prescribing. ${ }^{8}$ Irrational 
design of prescription is one of the important causes of medication error leading to the reduction in efficacy or enhancement in toxicity. Any misunderstanding created in transcription of prescription by a pharmacist or nurse could also leads to the use of a wrong medicine or wrong doses that may endanger the life of the patient or failure of the therapy

Prescription errors can largely be preventable forms of medication errors and there is a much scope for improvement in this area. It is better to define the nature and extent of the problem, before an attempt is made to improve it. Therefore, this study has been undertaken with an objective to generate the data on the prevailing prescription errors and their nature and extent. Just doing audit is not enough to change the prescribing habit of the prescriber. It needs a properly framed education session and evaluation of its impact to provide a fruitful effect. This type of audit along with of teaching session will be of great value to all the stake holders related with health care including the prescribers, administrators and governing bodies involved in the decision making and drafting policies.

\section{METHODS}

This was a cross sectional observational study conducted at Index medical college and hospital, Indore. Total of 320 prescriptions were collected in the form of photographs. Patients were approached for their prescriptions at the nearby pharmacies during the month of January 2019. Patients were explained the purpose of this study and their consents were taken prior to get their prescriptions with assurance of the privacy. Each of the prescription obtained in this way was photographed to record the contained information. Only freshly registered outpatients with their prescriptions belonging to all ages and both sex from all clinical departments were included to get the prospective data for this study. Prescriptions with only advised investigations or surgical procedure without any drug prescription were also excluded from this study. Analysis was done on core elements of prescriptions like Prescriber's information (name, degree, registration number, contact number). Essential patient's information (name, age, address of the patient and body weight for paediatric age group). Date of the prescription, clarity of the prescription (legibility), use of capital letters in hand written prescription, incorporation of essential non-pharmacological measures in the prescription, mention of the warning signals for the early recognition of the adverse events, mention of the warning in concern with food or drug interactions if applicable, signature of the prescriber.

Drug related information includes completeness in terms of the name of drug, dose, strength, route, frequency, duration and dosage forms of prescribed drugs, use of generic or brand names, number of drugs, fixed dose combinations, the use of unauthorized abbreviation. The observed data was expressed in number and percentage.

\section{RESULTS}

Total 320 prescriptions were reviewed. 284 (88.75\%) prescriptions contain complete prescriber information (name, degree, registration number, contact number). In 315 (98.44\%) prescriptions patient information were written correctly. Date and place was written in all prescriptions. Weight was not written in 3 pt that belong to paediatric age group and age was not written in 2 prescriptions. $240(75 \%)$ prescription were legible. Abbreviations were used in 310 (96.88\%) prescriptions. Completeness in terms of the name of drug, dose, strength, route, frequency, duration and dosage forms of prescribed drugs was seen in $252(78.75 \%)$ prescriptions. Use of capital letters in hand written prescription is seen in only $39(12.19 \%)$ prescriptions. In 311 (97.19\%) prescriptions, drugs were prescribed by brand name. In $101(31.56 \%)$ prescription letter contain drugs more than five. Less no. of prescriptions contains non pharmacological measure, warning signal to recognize adverse drug reactions of drugs, food and drug interaction information's related to prescribed drugs. Only few prescription were there which doesn't contain prescriber`s signature $(4.06 \%)$.

Table 1: Prescriber related information.

\begin{tabular}{|lll|}
\hline S. No. & Component or element & No. of prescription (\%) \\
\hline $\mathbf{1}$ & Patient information(age, address, date and place, weight) & $315(98.44)$ \\
\hline $\mathbf{2}$ & $\begin{array}{l}\text { Prescribers information (name, qualification, registration no. and contact } \\
\text { no. of prescriber) }\end{array}$ & $284(88.75)$ \\
\hline $\mathbf{3}$ & Legibility of prescription & $240(75)$ \\
\hline $\mathbf{4}$ & Diagnosis or complains & $270(84.38)$ \\
\hline $\mathbf{5}$ & Use of abbreviations & $310(96.88)$ \\
\hline $\mathbf{6}$ & Drug name in capital letter & $39(12.19)$ \\
\hline $\mathbf{7}$ & Drugs were prescribed by generic names & $9(2.81)$ \\
\hline $\mathbf{8}$ & Prescriptions that contain drugs more than 5 & $101(31.56)$ \\
\hline $\mathbf{9}$ & Use of fixed dose combinations & $205(64.06)$ \\
\hline $\mathbf{1 0}$ & Writing of warnings signal in concern with efficacy and adverse effect. & $3(0.94)$ \\
\hline $\mathbf{1 1}$ & Non-pharmacological measures or instruction to patients & $69(21.56)$ \\
\hline $\mathbf{1 2}$ & Prescriber's signature & $307(95.94)$ \\
\hline
\end{tabular}


Table 2: Drug related information.

\begin{tabular}{|lll|}
\hline S. No. & Component or element & \% error present \\
\hline $\mathbf{1}$ & Name of drug & Nil \\
\hline $\mathbf{2}$ & Dosage form & $4(1.25)$ \\
\hline $\mathbf{3}$ & Strength of drug & $21(6.56)$ \\
\hline $\mathbf{4}$ & Route of administration & $8(2.5)$ \\
\hline $\mathbf{5}$ & Frequency of administration & $15(4.69)$ \\
\hline $\mathbf{6}$ & Duration of treatment & $20(6.25)$ \\
\hline
\end{tabular}

\section{DISCUSSION}

Little mistake in interpretation of a prescription can result in worst outcome and such mistake can largely be prevented with increasing awareness. This study was to find out the common mistakes to enhance the awareness in future.

In our study $98.44 \%$ prescription had an error free patient related information perhaps may be due to the use of computer software. Any way it's good to have error free information since it is must for proper identification of a patient so that medicines are not administered to wrong patients. The same are also required for further communication and follow up of patients. Only 3 paediatric patient prescriptions doesn't have weight mentioned and 2 prescription doesn't contain age. Weight is particularly important in paediatric patient as it helps in calculation of dose of drugs.

All the prescriptions were showing the date again due to the use of computer software. Date is essential to clarify the treatment plan duration and to avoid unnecessary filling and future misuse of medicines.

$88.75 \%$ prescriptions have prescriber's information like name, degree, registration no. and department. This result is far better than that reported from Nepal, where $99.6 \%$ of prescriptions were deficient in this component. ${ }^{9}$ This is because most of the clinicians are now using their personalized stamps. A rational prescription also needs the contact phone or mobile number for the timely contact in case if any confusion related to medication administration or if any additional information is to be shared. It was disappointing to note that contact number was not mentioned on any of the prescription generated during hospital practice.

Prescription should be in clear handwriting. No overwriting is permitted. In our study 240 (75\%) were legible. $25 \%$ prescription were with poor handwriting (illegible). Occurrence of illegibility in our study is far less in comparison to that reported in study of Saudi Arabia (64.3\%), but more in comparison to that reported from Sudan (15.8\%) and Ethiopia (15\%), Brazil (6.6\%) and Nepal $(0.63 \%) .^{9-13}$ Illegible prescription can lead to misunderstanding leading to an error in dispensing or administration by pharmacist or nurse respectively.
Poor handwriting is a well-known and preventable cause of dispensing error. ${ }^{14}$ WHO emphasizes the clarity and legibility of prescriptions as the legal duty of the doctor. ${ }^{8}$

If drugs name are written in capital letter, it will be clearer and chances of error will also decrease. In our study only $12.19 \%$ prescription contains drug in capital. This writing habit can be changed by repeated session on prescriptions.

The omission of diagnosis was found only in $15.62 \%$ prescriptions much better than those reported from Saudi Arabia (33.3\%) and Sudan (94\%). ${ }^{10,13}$ Sometimes diagnosis or even presenting complains helps the pharmacist to eliminate the misunderstanding and dispensing of the wrong drug. This is considered to be the single most important measure to prevent dispensing errors. $^{14}$

$96.88 \%$ prescriptions were with the use of abbreviations. Though abbreviations were used in old medical practice because of time saving and convenient procedure yet they are the principle reasons beyond misinterpretation by pharmacist, nurse or by patient. This could make the drug less effective or more toxic. Only common and internationally accepted abbreviations should be used to prevent possible medication errors. ${ }^{8,15}$ The Institute for Safe Medication Practices provides a list of error-prone abbreviations, which are being frequently misinterpreted and involved in harmful medication errors. ${ }^{16}$ These abbreviations, symbols, and dose designations should never be used when communicating medical information.

Only $2.81 \%$ prescription contains drugs written in generic name. This figure is comparable to Balbir et al study which show $4.16 \%$ drug were prescribed by generic name. ${ }^{17}$ However it is too low as compared to other Indian studies many of which have even reported up to $73.4 \%$ usage of generic name. ${ }^{18}$ Drug prescribed by brand name may be more expensive as compare to generic drug. Non-availability of all the brands or lack of knowledge on all the available brands by the pharmacist may create a problem.

$31.56 \%$ prescriptions contain drugs more than 5 drugs. Poly pharmacy may increase the risk of hospitalizations, and medication errors. ${ }^{19,20}$ It also leads to increased costs, non-adherence to treatment, increased rate of patient 
morbidity and mortality. ${ }^{21,22}$ Polypharmacy may be useful in certain disease but it must outweigh the risk associated with therapy.

In our study $64.06 \%$ prescription contain at least one fixed dose combination. Fixed dose combination (FDC) were commonly used for common cold, diarrhoea, pain, gastroesophageal reflux disease. Use of FDC was less than the study of Balbir et al $(97.91 \%)$ and Kastury et al $(75 \%)$ but more than Chakrabarti et al $(59 \%) .{ }^{23,24}$ Uses of FDCs have some advantages like synergistic action and increased efficacy, reduced adverse effects, and improved patient compliance. However, there are certain disadvantages like increased cost, incompatible pharmacokinetics and toxicity.

$21.25 \%$ prescriptions contain drug related error (name of drug, dosage form, strength of drug, route of administration, duration of treatment). This significant amount of error cannot be tolerated as it may harm the patient.

A rational prescription should also incorporate the specific advice in concern with the drug or the disease i.e., to recognize the warning signals suggestive of adverse event or worsening of the disease. Such instructions were lacking in the prescriptions. Special warning if applicable with the drugs may prevent emergencies. They should clearly be written and informed to the patients. Non-pharmacological measures may improve the outcome of the treatment and must be mentioned. Prescriber's signature was missing in $4.06 \%$ prescriptions. Presence of signature is must to validate a prescription.

\section{CONCLUSION}

Prescription auditing has the great potential to promote the rational usages of drugs and essential medicine. Any sort of morbidity or mortality due to error in prescription, or dispensing of drug is not tolerable. Our study show that there is great requirement of improvement in prescribing behaviour of physician like legibility of prescription, avoidance of abbreviations, writing of the drug name in capital letters in a hand written prescriptions, use of generic names, avoiding unnecessary poly pharmacy and irrational FDCs. To make the prescription more rational there should be written incorporation of non- pharmacological measures and signals forecasting the adverse event and worsening of the condition. Regular continuing medical education, workshop, training session and prescription audit must be planned to change the prescribing habits for an error free rational prescription. Use of printed prescription could also improve many of these aspects.

\section{ACKNOWLEDGEMENTS}

We would like to thank Index Medical College which allows us to perform this study without any hindrance.
Funding: No funding sources Conflict of interest: None declared

Ethical approval: The study was approved by the Institutional Ethics Committee

\section{REFERENCES}

1. Dean B, Vincent C, Schachter M, Barber N. The incidence of prescribing errors in hospital inpatients: an overview of the research methods. Drug Saf. 2005;28:891-900.

2. Dean B, Schachter M, Vincent C, Barber N. Prescribing errors in hospital inpatients: their incidence and clinical significance. Qual Saf Health Care. 2002;11:340-4.

3. Kuo GM, Phillips RL, Graham D, Hickner JM. Medication errors reported by US family physicians and their office staff. Qual Saf Health Care. 2008; 17:286-90.

4. Ross S, Bond C, Rothnie H, Thomas S, Macleod MJ. What is the scale of prescribing errors committed by junior doctors? A systematic review. $\mathrm{Br} \mathrm{J}$ Clin Pharmacol. 2009;67:629-40.

5. Lesar TS, Briceland L, Stein DS. Factors related to errors in medication prescribing. JAMA. 1997;277:312-7.

6. Nadeem S, Shah H, Aslam M, Avery AJ. A survey of prescription errors in general practice. Pharm J. 2001;267:860-2.

7. Ansari M, Neupane D. Study on determination of errors in prescription writing: A semi-electronic perspective. Kathmandu Univ Med J. 2009;7(27):238-41.

8. DeVries TPGM, Henning RH, Hogerzeil HV, Fresle DA. Guide to good prescribing: A practical manual. Geneva: World Health Organization; 1994.

9. Ansari M, Neupane D. Study on determination of errors in prescription writing: A semi-electronic perspective. Kathmandu Univ Med J. 2009;7(27):238-41.

10. Irshaid YM, Homrany MA, Hamdi AA, Yamoah KK, Mahfouz AA. Compliance with good practice in prescription writing at outpatient clinics in Saudi Arabia. East Mediterr Health J. 2005;11(5/6):922-8.

11. Makonnen E, Yoseph M, Berhane Y. Quality of prescription at a tertiary care pharmacy in Addis Ababa. Ethiop Med J. 2002;40:233-9.

12. Silva AMS. Inpatients medical prescription errors. Einstein. 2009;7(3):290-4.

13. Yousif E, Ahmed AM, Abdalla ME, Abdelgadir MA. Deficiencies in medical prescriptions in a Sudanese hospital. East Mediterr Health J. 2006;12(6):915-8.

14. Buxton ILO. Principles of prescription order writing and patient compliance. In: Brunton LL, Chabner BA, Knollmann BC, eds. Goodman and Gilman's The Pharmacological Basis of Therapeutics. 12th ed. New York, NY: McGraw Hill; 2011: 1879-1889.

15. Grahame-Smith DG, Aronson JK. Oxford textbook of clinical pharmacology and drug therapy. $3 \mathrm{rd} \mathrm{ed.}$ New Delhi: Oxford University Press; 2008: 173-188. 
16. List of Error-Prone Abbreviations. Available at: https://www.ismp.org/recommendations/error-proneabbreviations-list. Accessed on 2 September 2019.

17. Balbir K, Rani W. Prescription audit for evaluation of prescribing pattern of the doctors for rational drug therapy in a tertiary care hospital. J Drug Delivery Therapeutics. 2013;3(5):77-80.

18. Karande S, Sankhe P, Kulkarni M. Patterns of prescription and drug dispensing. Indian $\mathbf{J}$ Pediatr. 2005;72:117-21.

19. Winterstein AG, Sauer BC, Hepler CD, Poole C. Preventable drug-related hospital admissions. Ann Pharmacother. 2002;36(7-8):1238-48.

20. Michocki RJ, Lamy PP, Hooper FJ, Richardson JP. Drug prescribing for the elderly. Arch Fam Med. 1993;2(4):441-4.

21. Incalzi RA, Gemma A, Capparella O, Terranova L, Porcedda P, Tresalti E, et al. Predicting mortality and length of stay of geriatric patients in an acute care general hospital. J Gerontol. 1992;47(2):35-9.

22. Linjakumpu T, Hartikainen S, Klaukka T, Veijola J, Kivela SL, Isoaho R. Use of medications and polypharmacy are increasing among the elderly. J Clin Epidemiol. 2002;55(8):809-17.

23. Kastury N, Singh S, Ansari KU. An audit of prescription for rational use of fixed dose drug combinations. India J Pharmacol. 1999;31:367-9.

24. Chakrabarti A. Prescription of fixed dose combination drugs for diarrhoea. Indian $\mathbf{J}$ Med Ethics. 2007;4:165-7.

Cite this article as: Patel $\mathrm{P}$, Bhora M, Vishwe A, Nyati P, Tripathi S, Gupta K. Prescription audit to evaluate the pattern and errors in a tertiary care hospital. Int J Basic Clin Pharmacol 2019;8:2650-4. 